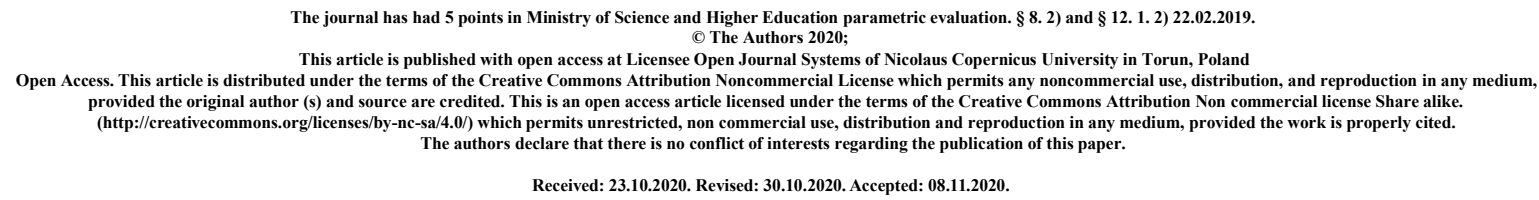

\title{
Neurosurgery education of medical students in Nicolaus Copernicus University during the COVID-19 pandemic
}

\author{
Zygmunt Siedlecki, Karol Nowak, Maciej Śniegocki
}

Department of Neurosurgery, Neurotraumatology and Pediatric Neurosurgery, The Ludwik Rydygier Collegium Medicum in Bydgoszcz, The Nicolaus Copernicus University in Torun

Corresponding address:

Dr. med. Zygmunt Siedlecki Department of Neurosurgery, Neurotraumatology and Pediatric Neurosurgery,

the Ludwik Rydygier Collegium Medicum in Bydgoszcz,

ul. Skłodowskiej-Curie 9

85-094 Bydgoszcz

tel.: + 48606302680

e-mail: siedlecki@cm.umk.pl 


\begin{abstract}
We present a short article on the actual state of education and didactics in the Department of Neurosurgery during the COVID-19 pandemic. The pandemic disrupted the education of students in the 2019/2020 and 2020/2020 academic years. From March 2020, there are no traditional classes with students and they have been deprived the possibility of patients examining and participating in surgical procedures. Only on-line classes are conducted by the use of Microsoft Teams and by e-mail contact. We emphasize that this is unprecedented situation in history of clinical medicine education. We also affirm difficulty of surgical medical specializations training by e-learning. Due to the practical nature of neurosurgery, we provide numerous neuroimaging and videos of surgical procedures using Microsoft Teams. The effects of on-line education of surgical sciences, including neurosurgery, can be assessed after a longer period of time. Currently, in the new reality that surprised unexpectedly medical academics in 2020, we are unable to interpret it.
\end{abstract}

Key words: education, COVID-19, e-learning, medical students

\title{
Introduction
}

The COVID-19 pandemic caused a lock-down in March 2020 and resulted in the abandonment of traditional education at all levels, including the topic of university education [1]. In order to prevent the spread of SARS-CoV2, student groups have been abandoned and, in the case of medical students, it has become necessary to avoid contact between students, university teachers (doctors or other medical professionals) and patients [1].

The authorities of the Nicolaus Copernicus University on March 24, 2020 decided to discontinue traditional education and conduct online learning. The following platforms have been recommended: 1) Microsoft Teams; 2) Moodle e-learning platform; 3) BigBlueButton videoconference system. It was recommended to avoid sending files containing didactic materials (e.g. presentations) with the use of USOSweb due to the possibility of technical problems. Technical support for teachers conducting classes in a remote form using the tools referred to in section 1, was provided by the University Information Center.

As university teachers at Collegium Medicum im. L. Rydygiera in Bydoszcz, teaching 
neurosurgery, we decided to educate students through as shown in Figure 1.

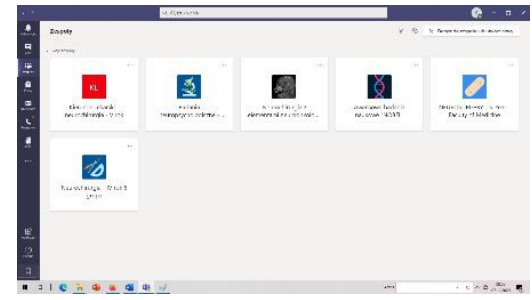

Figure 1. Microsoft Teams - basic screen with students groups

Microsoft Teams enables the creation of student groups to conduct classes, lectures, seminars and exercises. This allows you to send presentations, photos and educational materials.

At the beginning of such educational system, being surprised by new realities and the difficulty of combining student education with work in a hospital, we also conducted e-mail correspondence with students. We sent students presentations and descriptions of clinical cases by e-mails. Besides, we got to know the technical aspects of Microsoft Teams better.

\section{Current status - neurosurgery education of medical students}

The Department of Neurosurgery conducts didactic classes with Faculty of Medicine students. Classes are conducted in the third, fourth, fifth and sixth year of medical studies, as presented in Table 1.

Table 1. Classes in neurosurgery for medical students

\begin{tabular}{|c|c|c|c|c|c|c|}
\hline Subject & year & $\begin{array}{l}\text { Type of } \\
\text { classes }\end{array}$ & $\begin{array}{l}\text { Hours } \\
\text { - total }\end{array}$ & $\begin{array}{l}\text { Hours } \\
\text {-TR* }\end{array}$ & $\begin{array}{l}\text { Hours - } \\
\text { on line }\end{array}$ & ECTS \\
\hline $\begin{array}{l}\text { neurosurgery with elements of } \\
\text { neurooncology }\end{array}$ & 4 & seminars & 12 & 12 & 0 & 0,4 \\
\hline $\begin{array}{c}\text { neurosurgery with elements of } \\
\text { neurooncology }\end{array}$ & 4 & exercise & 16 & 16 & 0 & 0,53 \\
\hline $\begin{array}{l}\text { neurosurgery with elements of } \\
\text { neurooncology }\end{array}$ & 4 & seminars & 12 & 12 & 0 & 0,4 \\
\hline $\begin{array}{l}\text { neurosurgery with elements of } \\
\text { neurooncology (english) }\end{array}$ & 4 & exercise & 16 & 16 & 0 & 0,53 \\
\hline surgery & 6 & exercise & 120 & 120 & 0 & 0,53 \\
\hline surgery - neurosurgery & 5 & lectures & 18 & 0 & 18 & 0,6 \\
\hline surgery - neurosurgery & 5 & exercise & 16 & 16 & 0 & 0,53 \\
\hline surgery - neurosurgery (english) & 5 & seminars & 18 & 18 & 0 & 0,4 \\
\hline surgery - neurosurgery (english) & 5 & exercise & 16 & 16 & 0 & 0,53 \\
\hline $\begin{array}{l}\text { neurosurgery for interested } \\
\text { students }\end{array}$ & 4 & exercise & 15 & 15 & 0 & 0,5 \\
\hline
\end{tabular}

*preferred for traditional learning 
Table 1 shows the number of hours in neurosurgery for each group of students. By creating this table in September 2020, we hoped that the traditional, stationary learning would be feasible. As practicing neurosurgeons and university teachers, we put emphasis on possibility of direct conversation with students and involving them in everyday clinical practice.

Therefore, we assumed that only the lectures would be conducted on-line, and that both seminars and exercises would be traditional. We were also inclined to organize seminars in a hybrid, partially remote form, while we wanted to conduct the exercises in a traditional way, with a view to adequate education of future medical professionals.

In the Department of Neurosurgery of Collegium Medicum im. L. Rydygier in Bydgoszcz, Nicolaus Copernicus University, neurosurgery has been teaching for about 40 years. Previously, before the fusion with the University, this department was a unit of the Medical Academy in Bydgoszcz. From the very beginning, the main emphasis on educating students was on practice. Students examined patients and participated in their treatment. Most importantly, students were always taken to the operating room and a very large part of their education took place there. During the operating procedures, the students watched them, were able to assist and perform basic surgical activities, such as suturing the skin. The neurosurgeons who carried out the procedures explained to the students the essence of the procedure, the surgical technique. In this way, students gained knowledge, skills and familiarity with everyday neurosurgical practice.

Unfortunately, the escalating second wave of the COVID-19 pandemic prevented us from implementing education in such a system. All learning takes place remotely through Microsoft Teams. Using this platform, we provide students with knowledge about neurosurgical diseases. We deal with the topics of brain tumors, aneurysms, vascular malformations, brain and spine injuries and spine surgery. For the purposes of such teaching, graphic presentations have been created to help students understand the mechanisms of brain diseases, as shown in Figure 2.

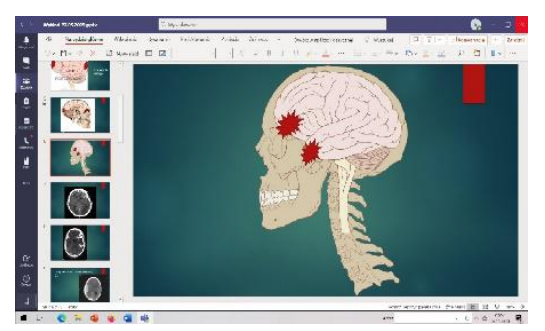

Figure 2. Microsoft Teams - explanation of the brain contusion mechanism for students 
As ordered by the university authorities, classes are conducted in a synchronous and asynchronous manner. We make every effort to ensure that most classes are conducted in a synchronous manner, i.e. by conducting a conversation. We emphasize that synchronicity is problem learning. During such classes, we discuss with students, give them clinical issues and encourage them to deduce.

In addition, as asynchronous classes, we send clinical case reports and test questions. We emphasize that the test questions resemble those from the Final Medical Examination (pol. Lekarski Egzamin Końcowy, LEK). It was similar with the rest during traditional classes. Currently, our educational materials and presentations have many photos of the operating procedures performed, as shown in Figure 3.

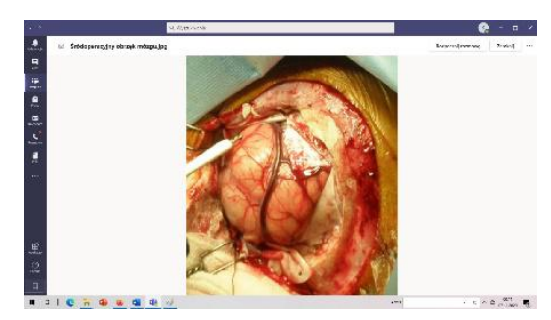

Figure 3. Microsoft Teams - picture of intraoperative cerebral edema

\section{Discussion}

Since the spread of the COVID-19 pandemic, i.e. from 2020, many authors have raised the issue of online education, also with particular emphasis on university education in neurosurgery at medical faculties.

Rajab et al. (2020) analyzed the impact of the COVID-19 pandemic on online education at the College of Medicine (COM) of Alfaisal University in Riyadh, Saudi Arabia. He e-mailed to 1,289 students and faculty members of the COM [2]. Rajab et a. noted that $41.8 \%$ reported respondents,having little or no online teaching/learning experience before the pandemic, and majority of tchem preferred blending online and face-to-face instruction [2]. In Rajab's study, most of the respondents $(70.7 \%)$ believed that the COVID-19 pandemic has boosted their confidence in the effectiveness of online medical education [2]. In accordance with our opinion - the university teachers of the Nicolaus Copernicus University, Rajab also emphasizes that the long-term effects of this situation and how it will affect the knowledge of future graduates of the Faculty of Medicine will probably turn out after many years [2]. 
Tomlinson et al. (2020) indicates a problem that in an era in which social distancing seems the most effective measure for limiting disease transmission, medical students have been banished from the wards which may have adverse repercussions on their future work experience and practical skills [3].

Lewis et al. (2020) described neurosurgery education during COVID-19, however, contrary to our work, he focused on educating resident neurosurgery rather than teaching university medical students [4]. He pointed out that neurosurgical community has made a tremendous adjustment through the use of communications tools [4]. Online conference platforms hav eallowed the continuance of educational conferences and patientcase discussions. According to Lewis, virtual conferences allow the neurosurgical resident to continue a dedicated approach to their education, and more importantly, to the care of patients [4].

Wong et al. (2020) noted that in topic of medical students education, multimodal communication approach is helpful, using email, YouTube video messages, and website postings [5]. Wong also emphasis that early engagement of internal (university administration) and external (health authorities) stakeholders is crucial [5]. According to Wong, during the pandemic, all aniversity teachers are learning that medical curricular adaptations should be flexible in terms of delivery and administration, building on the existing pedagogical design [5]. Wong also emphasis that governance structure of the curriculum should be maintained to ensure compliance with accreditation standards [5].

Rastegar Kazerooni et al. (2020) in turn discussed the issue of peer mentoring for medical students during pandemic via a social media platform. Rastegar Kazerooni emphasized and put attention that by experience achieved through working with junior students during COVID-19, senior medical students found themselves increasingly able to provide timely and appropriate psychological advice for others [6]. According to Rastegar Kazerooni, experience appeared to be as important for professional growth as it was for the psychological relief of more junior students [6]. In resonance with the maxim that ,teaching is learning twice” [6] Rastegar Kazerooni noted that by taking on peer mentoring leadership responsibility, senior students can further develop the skills needed to be competent physicians [6]. Experiences published by Rastegar Kazerooni constitute a valuable consideration in the teaching of medical students. We emphasize that Microsoft Teams of which we teach neurosurgery also enables students to create discussion and research groups. As university teachers, we encourage students to such activity and mobilize them to professional, scientific and social activities. 


\section{Conclusions}

The unexpected change of education concept in practical fields of medicine is surprise to university teachers. Students have been deprived the possibility of practicing in a hospital, examining patients and assisting in medical procedures, which seems unfavorable to their professional development. Academic teachers who are neurosurgeons are also not able to share their experience to a satisfactory extent. Due to fact that this manuscript is published during the second wave of the COVID-19 pandemic, it will only present the current signaling of the problem. The long-term effects of this situation and how it will affect the knowledge of future graduates of the Faculty of Medicine will probably turn out after years.

Competing Interests: The authors declare that they have no conflict of interest.

Acknowledgements: The authors thank the dean's authorities, the administration of Collegium Medicum and medical students for their support in the new education system.

\section{References}

1. Ferdig, R. E., Baumgartner, E., Hartshorne, R., Kaplan-Rakowski, R., \& Mouza, C. (2020). Teaching, technology, and teacher education during the covid-19 pandemic: Stories from the field. Waynesville, NC, USA: Association for the Advancement of Computing in Education (AACE).

2. Rajab, M. H., Gazal, A. M., \& Alkattan, K. (2020). Challenges to online medical education during the COVID-19 pandemic. Cureus, 12(7).

3. Tomlinson, S. B., Hendricks, B. K., \& Cohen-Gadol, A. A. (2020). Innovations in neurosurgical education during the COVID-19 pandemic: is it time to reexamine our neurosurgical training models?. Journal of Neurosurgery, 1(aop), 1-2.

4. Lewis, C. T., Zeineddine, H. A., \& Esquenazi, Y. (2020). Challenges of neurosurgery education during the coronavirus disease 2019 (COVID-19) pandemic: a US perspective. World neurosurgery, 138, 545-547.

5. Wong, R. Y. (2020). Medical education during COVID-19: lessons from a pandemic. BCMJ, 62(5), 170-171. 
6. Rastegar Kazerooni, A., Amini, M., Tabari, P., \& Moosavi, M. (2020). Peer mentoring for medical students during COVID-19 pandemic via a social media platform. Medical education. 